http://www.jfas.info

\title{
LIGHTNING IMPULSE INVESTIGATION ON VEGETABLES OILS AND SIMULATION OF ELECTRIC FIELD DISTRIBUTION
}

\author{
N. A. M. Amin, M. T. Ishak ${ }^{*}$, N. I. A. Katim, M. H. A Hamid, F. R. Hashim and M. F. M. Din \\ Faculty of Engineering, National Defence University of Malaysia, SungaiBesi Camp, 57000 \\ Kuala Lumpur, Malaysia
}

Published online: 10 September 2017

\begin{abstract}
Vegetable oils such as Palm Oil (PO) and Coconut oil (CO) are being considered as substitutions to mineral oil in power transformers. Lightning impulse strength is important for insulation design of power transformer and routine test for high voltage power transformer in industries. This paper covers the testing of the lightning impulse breakdown voltages of Coconut Oil (CO) and Palm Oil (PO) relative to Mineral Oil (MO) under quasi-uniform field. Furthermore, understanding the performance of breakdown voltages and electric field distribution in the insulating oil of a transformer during transient is important. Therefore, in this paper, electric field analysis was performed to evaluate the effect of the input voltage condition on electric field distribution. ANSYS software was used for perform electric field calculations based on the finite element methods.
\end{abstract}

Keywords: vegetable oil; lightning impulse; electric field; breakdown voltage; finite element; power transformer; transient; quasi uniform; ANSYS.

Author Correspondence, e-mail: mtaufiq@upnm.edu.my

doi: http://dx.doi.org/10.4314/jfas.v9i3s.30 


\section{INTRODUCTION}

Most of transformers in the power system network are oil filled types. Oil is known as a crucial part of the insulation system in transformers apart from cellulose. For many years, various research works were carried out on different aspects such as safety/environmental, ageing and electrical performance of vegetable oil. Transformer filled with vegetable oil were already tested successfully at different voltage level [1]. Among the attractive factors of vegetable oil is the non-toxicity and highly biodegradable, which ensure low risk to the environment if there is a spillage. The high flash and fire points of vegetable oil ensure more in-service operating safety than mineral oil.

Moreover, vegetable oil such as natural ester could also slow down the ageing rate of cellulose insulation through water scavenging and hydrolytic protection mechanism [2-3]. Apart from natural ester, palm based oil is another type of vegetable oil that can be used as dielectric insulating fluid in transformers. The chemical characteristics of palm based oil are almost close to natural ester such as it is biodegradable, has high fire and flash point and it is non-toxic due to most of palm base oil is from food grade type [4]. Although ester liquids have proven by other researchers about their applicability in distribution transformer and small sized power transformers, for transmission power transformer application the quality and properties of oils need to be further investigated. In this present work, the performance of the lightning impulse of Mineral Oil (MO), Coconut Oil (CO) and three types of Palm Oil (PO) is examined.

Lightning impulse breakdown voltage test is carried out under quasi-uniform field [5-6]. In addition, a simulation on sphere-to-spherecopper electrode configuration will be assessed to see the effect on electric field when subjected to high voltage. This simulation is proposed to validate the experimental results. The models in this paper are based on three-dimensional (3D) axial symmetric model dependent transient equations to determine the electric potential of the test object, which is solved by the ANSYS software. The test model was set up according to IEC 60897 [7]. The models are conducted to study the effects of the magnitude of the electric field at standard gap distance and electrode types on the transient process. 


\section{EXPERIMENTAL DESCRIPTION}

\subsection{Test Samples}

The samples used in the experiment were MO, CO and three types of PO. PO samples were obtained from readily available cooking oil products in the market and all of them are Refined, Bleached, Deodorized Palm Oil(RBDPO)Olein type. Table 1indicates the characteristics of these RBDPOs. RBDPOA and RBDPOC have the highest content of mono-unsaturated fat followed by RBDPOB and CO. On the other hand, RBDPOC has the highest content of poly-unsaturated fat followed by RBDPOB, RBDPOA and CO. RBDPOC also has the highest content of vitamin E followed by RBDPOB and RBDPOA, while CO has no vitamin E.The samples were first filtered by a membrane filter with a pore size of $0.2 \mu \mathrm{m}$. Next, all samples were dried in an air circulating oven at $85{ }^{\circ} \mathrm{C}$ for 48 hours and rested at ambient temperature for a further 24 hours before tested for lightning impulse voltage.

\subsection{Lightning Breakdown Voltage}

The lightning impulse breakdown voltage was carried out according to IEC 60897 [7]. The test configuration can be seen in Fig.1 [8-9]. Sphere-to-sphere copper electrode configuration was used to represent the quasi-uniform field at a gap distance of $3.8 \mathrm{~mm}$. The diameter of the sphere electrodes is $12.7 \mathrm{~mm}$. A standard lightning impulse voltage, 1.2/50 $\mu$ s was produced by a 2 -stage TERCO impulse generator with a maximum voltage $280 \mathrm{kV}$. The test was carried out under positive lightning impulse.

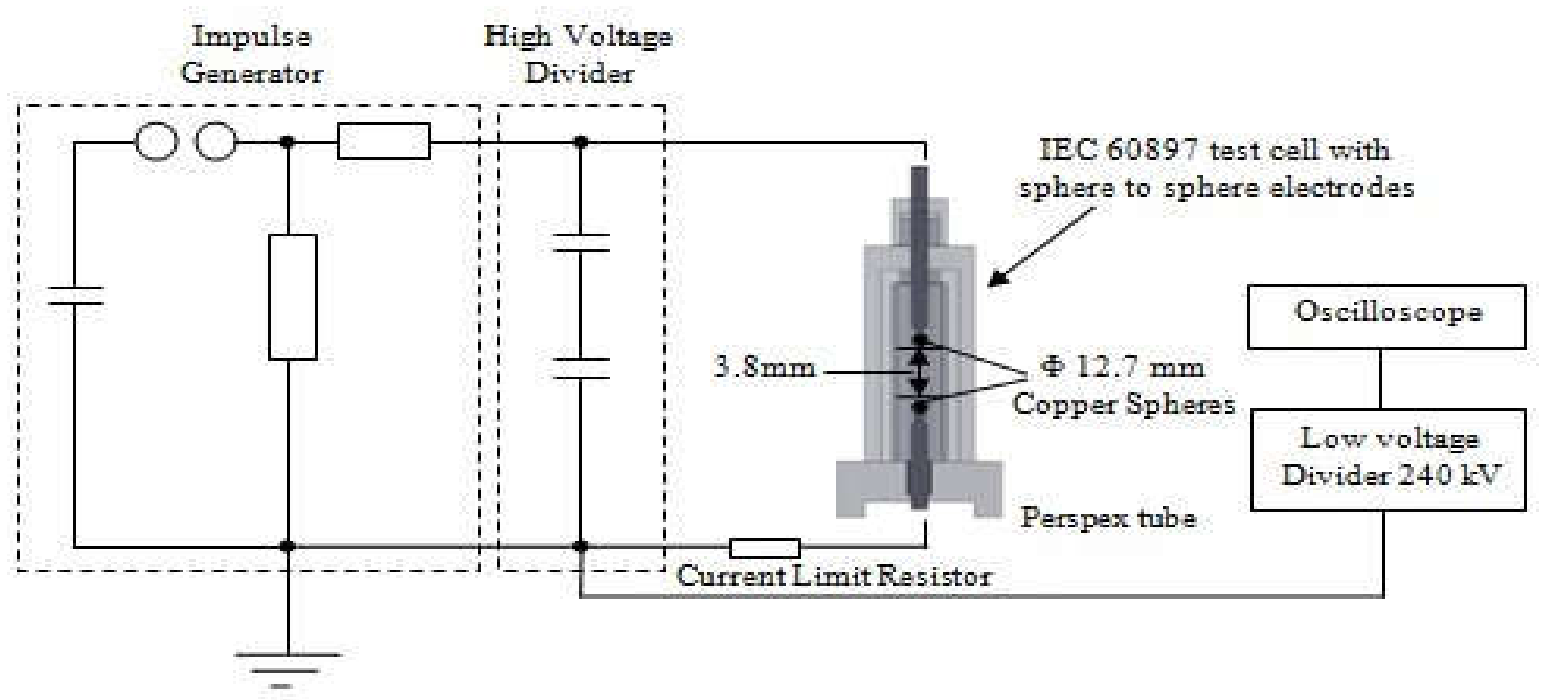

Fig. 1. Test configuration for lightning impulse[8-9] 


\subsection{Simulation by ANSYS Software}

A simplified model of the test cell was used to perform the lightning impluse waveform. In order to prove the strength and potential value of different types of oil, finite element methode was done under different applied voltages. The applied voltage were adjusted from $0 \mathrm{~V}$ to $80 \mathrm{kV}$. Understanding the potential and electric field distribution in the insulation system of a transformer during transient is vital to its construction. A 3-D asymmetrical electric field finite element analysis is performed to determine electric fields through the electrodes replicate the windings in transformer using ANSYS software.

\section{RESULTS AND DISCUSSION}

\subsection{Breakdown Voltage}

The 50\% lightning breakdown voltages for PO, RBDPOB, CO and MO can be seen in Table 1 . The highest lightning breakdown voltage is MO with a value of $236.33 \mathrm{kV}$, followed by $\mathrm{CO}$, POA, POB and POC with values of $213.33 \mathrm{kV}, 206 \mathrm{kV}, 202.67 \mathrm{kV}$ and $200 \mathrm{kV}$ respectively. Only PO and $\mathrm{CO}$ have almost the same performance where the percentage of difference is less than $6 \%$.

Table 1. 50\% lightning breakdown voltage for gap distance $3.8 \mathrm{~mm}$

\begin{tabular}{cccccc}
\hline Voltage Polarity & MO (kV) & CO (kV) & POA (kV) & POB (kV) & POC (kV) \\
\hline Negative & 236.33 & 213.33 & 206 & 202.67 & 200 \\
\hline
\end{tabular}

As having that, Weibull distribution is used for modelling the breakdown voltages more accurate. The negative breakdown voltages at $1 \%$ and $50 \%$ probabilities of failure are shown in Table 2. The MO has higher breakdown probabilities among other oils. At 1\% probabilities of failure, POA is comparable to MO with percentage of difference is $1.13 \%$. In addition, the distribution of 15 breakdowns each sample is given in Fig. 2. The dispersion of three types of PO is closely the same.

\subsection{ANSYS Simulation of Lightning Impulse}

Testing with lightning impulse basically used to simulate the capability of the insulation component or material in withstanding the lightning surge strike. An impulse generator basically entails of a capacitor which is discharged through a circuit and charged to the 
required voltage. The waveform shown in Fig. 3 is the standard lightning impulse of 1.2/50 $\mu$ s duration with the peak voltage reached in $1.2 \mu$ s and the tail of the wave decaying to a level of $50 \%$ of the peak in $50 \mu$ s.

Table 2. Negative lightning breakdown voltages of all samples at gap distance $3.8 \mathrm{~mm}$

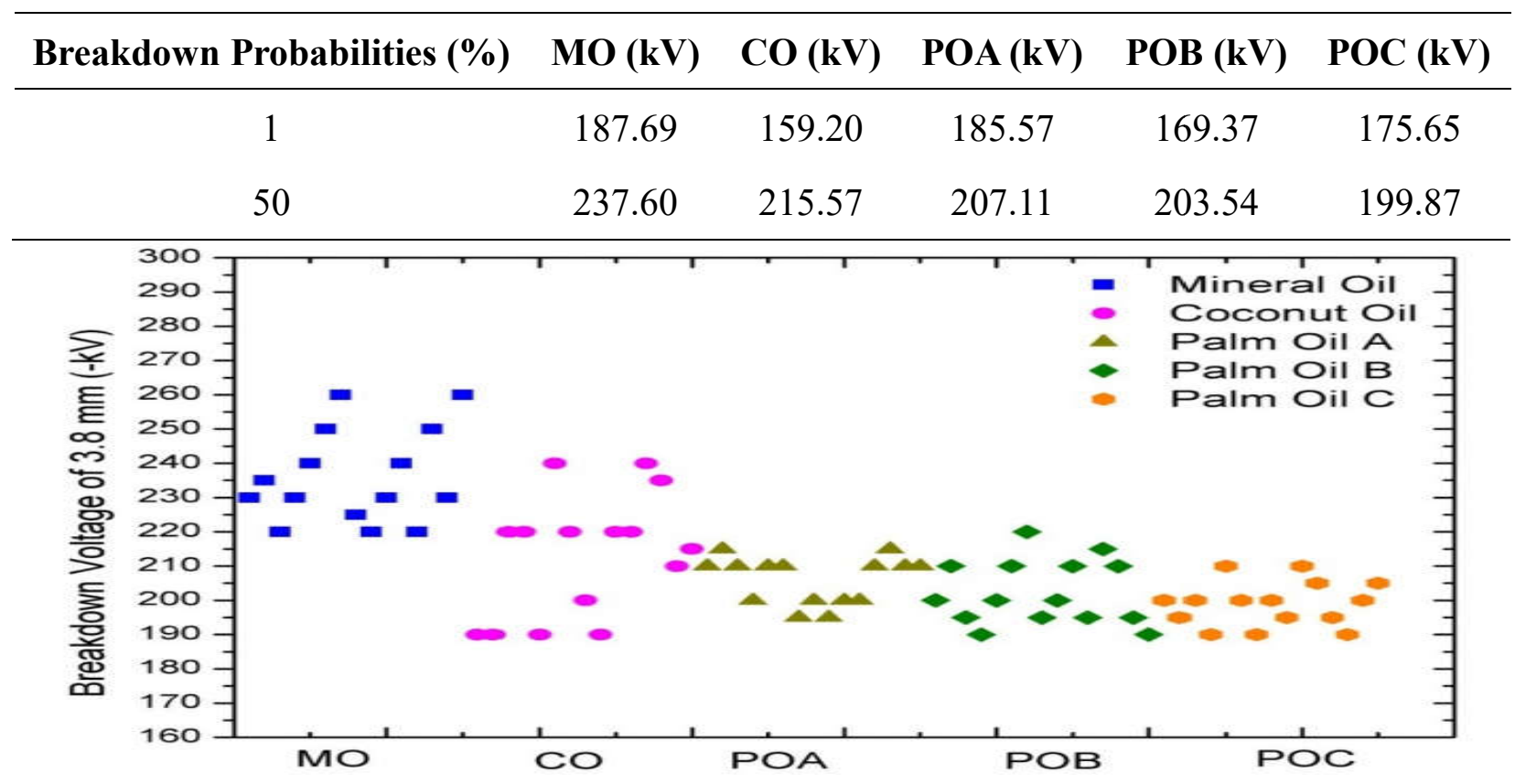

Fig. 2. The $50 \%$ breakdown voltage based on rising-voltage method of all samples

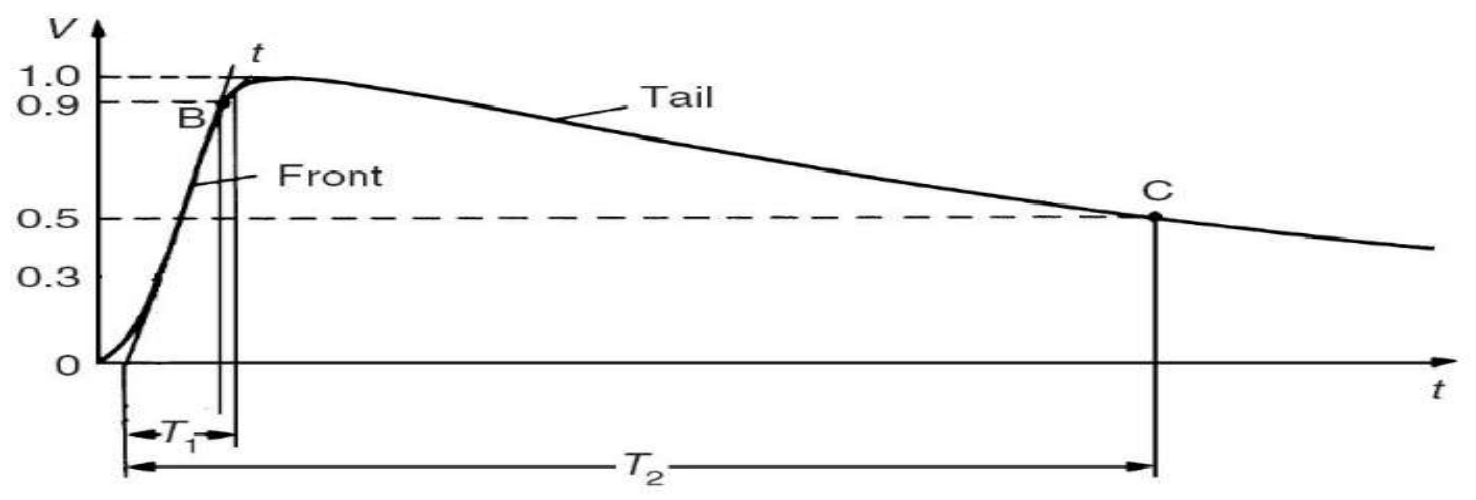

Fig. 3. Standard Lightning Impulse $1.2 / 50 \mu$ svoltage shape

$V=V_{o}\left(e^{-\alpha t}-e^{-\beta t}\right)$

Equation (1) indicates that lightning voltage can be corresponding to a doubly exponential curve as shown in Fig. 4. It increases quickly to the peak and falls quite slowly to zero values with respect to time axis. Lightning impulse voltage has a wave shape associated with it which can be given by use (1) where alpha, $\alpha=14700$ and beta, $\beta=2470000$ and $V_{o}$ is the charging voltage. The equation is applied in ANSYS simulation to see the wave of each 
samples.

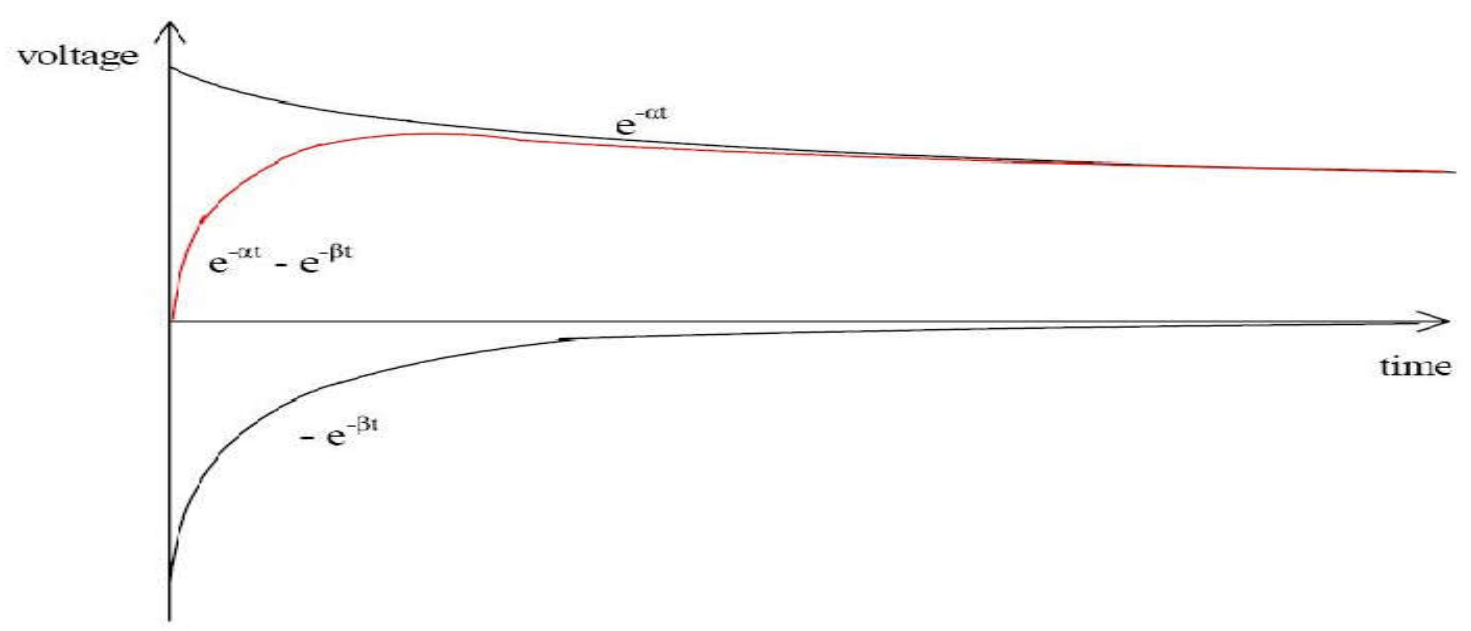

Fig. 4. Double exponential waveform

Properties of all samples are collected using ADTR-2K Plus, fully automatic dielectric constant, tan delta and resistivity test set. Table 3 shows the properties for five types of oil that are applied in the simulation.

Table 3. Properties of all samples

\begin{tabular}{cccc}
\hline Samples & Permittivity, $\varepsilon_{\mathbf{r}}$ & Resistivity, R $(\boldsymbol{\Omega} \cdot \mathbf{m})$ & Conductivity, $\boldsymbol{\sigma}(\mathbf{S} / \mathbf{m})$ \\
\hline MO & 1.535 & $119.7 \mathrm{~T}$ & $8.3542 \mathrm{e}^{-15}$ \\
CO & 1.605 & $231.5 \mathrm{G}$ & $4.3197 \mathrm{e}^{-12}$ \\
POA & 1.972 & $1.571 \mathrm{~T}$ & $6.3654 \mathrm{e}^{-13}$ \\
POB & 1.661 & $6.178 \mathrm{~T}$ & $1.6186 \mathrm{e}^{-13}$ \\
POC & 1.982 & $9.273 \mathrm{~T}$ & $1.0784 \mathrm{e}^{-13}$ \\
\hline
\end{tabular}

The simulated output waveform of lightning impulse is shown in Fig. 5. Meanwhile, Table 4 shows $1.2 / 50 \mu \mathrm{s}$ lightning breakdown voltages results of all samples. For specification of impulse waves their rise of front time, fall or tail time to $50 \%$ of peak value and peak value voltage is needed. These parameters are determined with the mathematical analysis as illustrated in Fig. 5 and Table 4 respectively.As per IEC, standard impulse voltage generators produces waves with $1.2-250 \mu$ s standard front time and 50-2500 $\mu$ s for tail time.Referring to the wave shape in Fig. 5 and as point up in Table 4, the rise time for all samples are comparable each other within 1.9 to $2.5 \mu \mathrm{s}$. Meanwhile, the total energy (mJ) also comparable with percentage of difference is $9 \%$ to $23.2 \%$. At this point, the MO states the highest among 
others followed by POA and POC. PO is much better than CO correspondingly.

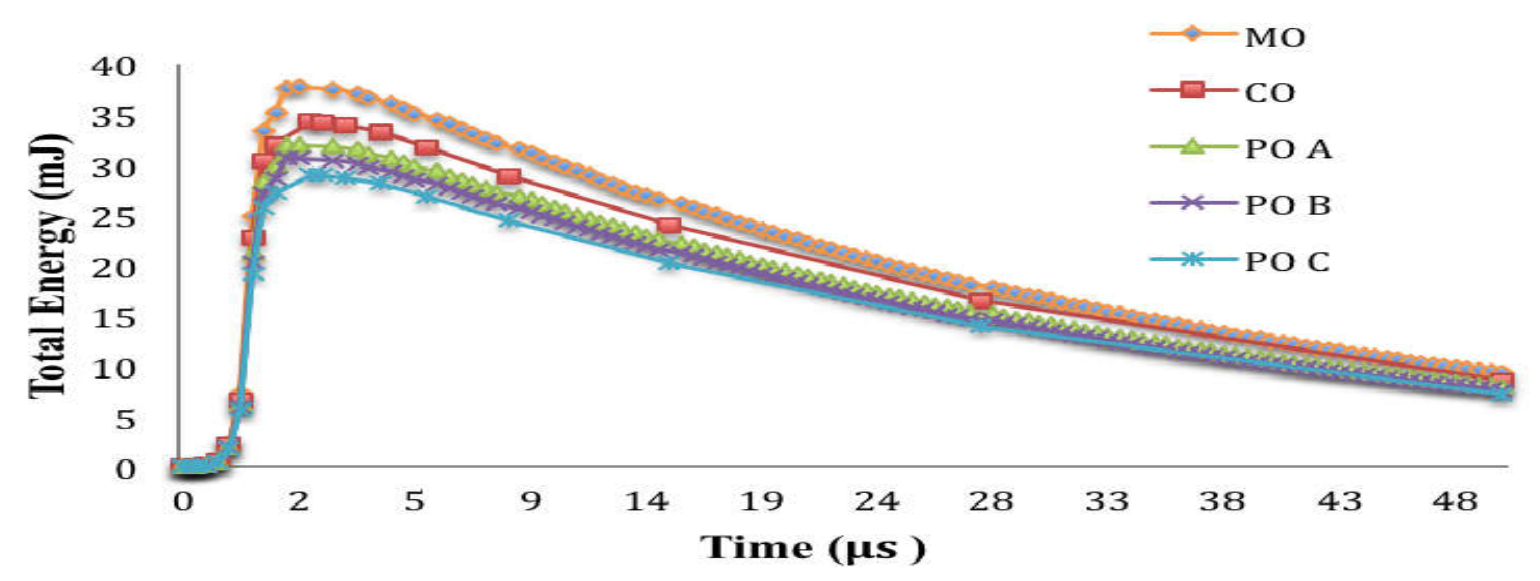

Fig. 5. Simulated lighning impulse output waveform total energy versus time $(\mu s)$

Table 4. $1.2 / 50 \mu$ slightning breakdown voltages results of all samples

\begin{tabular}{ccc}
\hline Samples & Total Energy $(\mathbf{m J})$ & Time $(\boldsymbol{\mu s})$ \\
\hline MO & 37.69 & 2.2 \\
CO & 30.63 & 2.2 \\
POA & 34.27 & 2.3 \\
POB & 28.95 & 2.5 \\
POC & 31.99 & 1.9 \\
\hline
\end{tabular}

\subsection{Relationship between Electric Field and Distance}

A typical test cell as shown in Fig. 1 is modelled in ANSYS software by real dimension. The electrodes are assigned by material of copper respectively. The investigationof electric field behavior of different oil samples at $3.8 \mathrm{~mm}$ gap distance showed in Fig. 6. Accordingly, Fig. 6 shows the simulation curve for all samples against with gap distance. All samples illustrated the same pattern but MO shows higher electric field and higher high breakdown voltage compared to $\mathrm{CO}$, POA, POB and POC.

In addition, Fig. 7 present clearly image for electric field vector or lines to better understand how the electric field move which give an indication of both size and the strength of the field after applied voltage. The field vector at any point gives the direction of the field at the point and the color of the vector shows the strength of the field. 


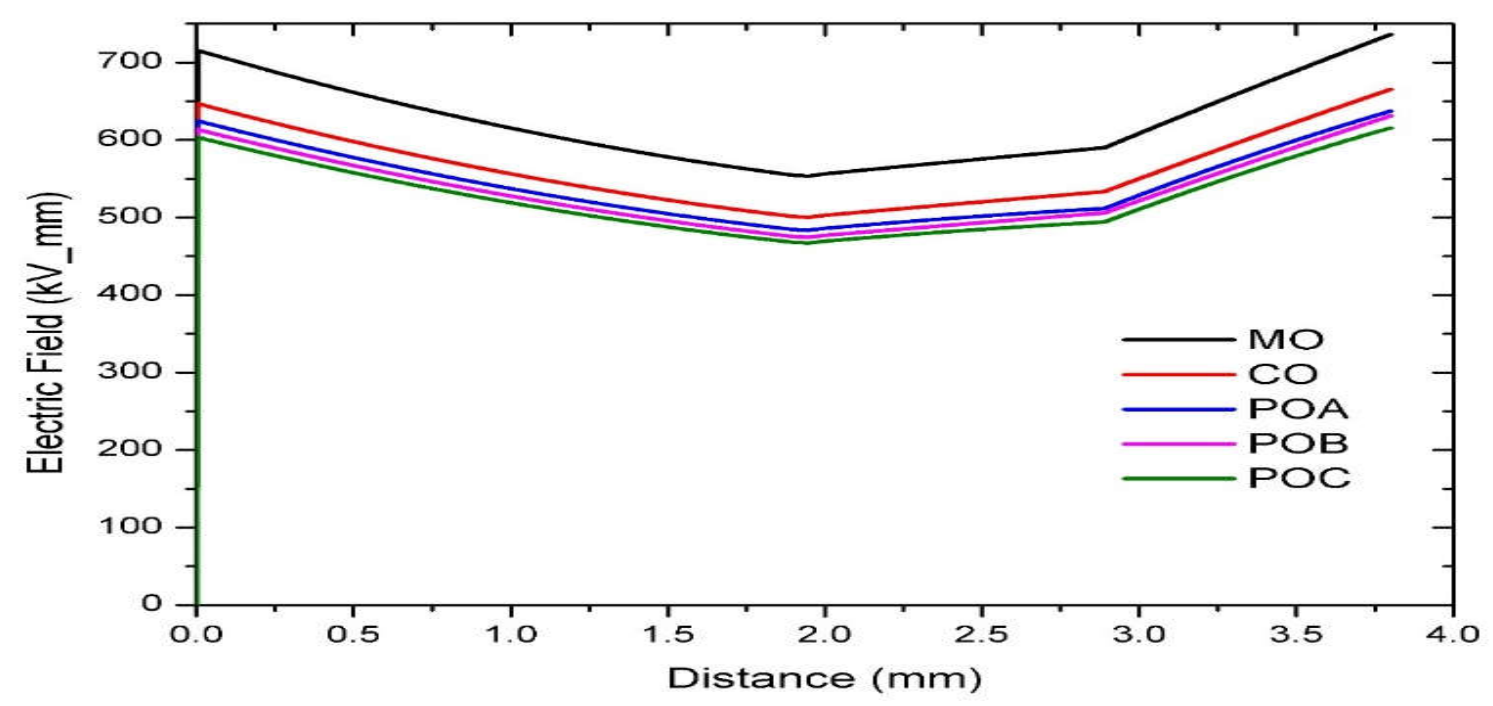

Fig. 6. Relationship between electric field and distances for five samples

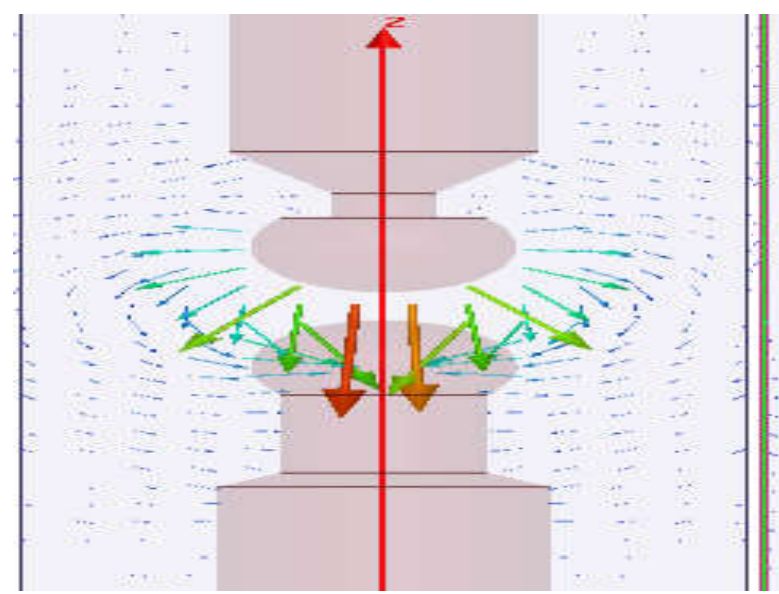

a) $\mathrm{MO}$

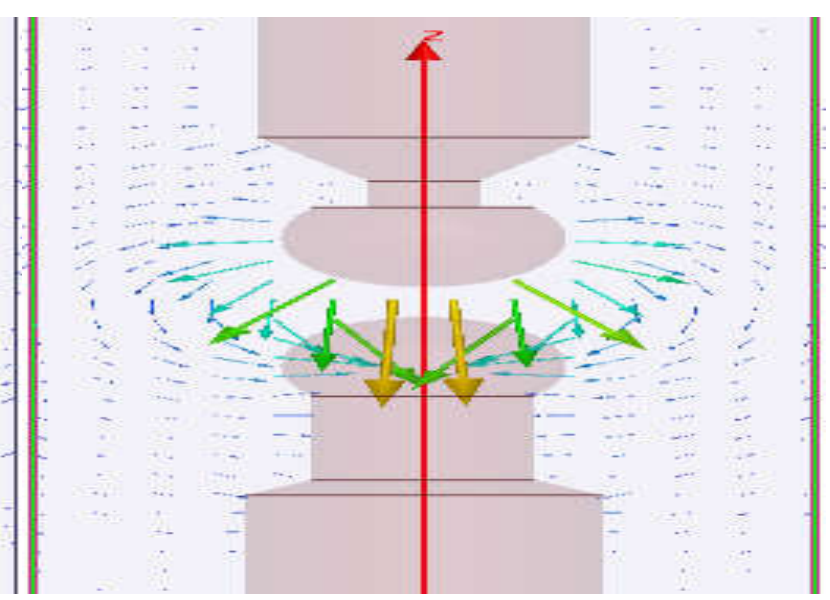

b) POC

Fig. 7. Electric field vector for MO and POC

In this present work, simulation on electrode set-up and gap spacing will be assessed to see the effect on electric field. Fig. 8 (a) to (e) explained clear figure of simulation how electric field shows around sphere after subjected to high voltage. The color code of electric field derive from the simulations is red, which is the strongest field, yellow to green for intermidiate electric field, blue for weaker field and then gradually fade away as the field decreses in magnitude. The variation type of electrode will give different result, as for this simulation electrode material assign as copper. Sphere-to-sphere configuration with diameter of $12.7 \mathrm{~mm}$ resulted a different electric field for each samples. Boundary condition is applied based on experimental results for each sample. From figure, MO shows strong electric field intensity followed by CO and PO respectively. 
Based on experimental, MO shows the highest breakdown voltages compared to other vegetable oils. Meanwhile, the electric field was found the same which is MO shows higher (red color) electric field nearer to the end surfaces of electrodes. Technically, by using finite element method, knows the maximum electric field between sphere electrode arrangements is proved that the breakdown occurs faster. It is observed that the electric field is maximum in vertical where the curvatures of the sphere electrodes more or less uniform.
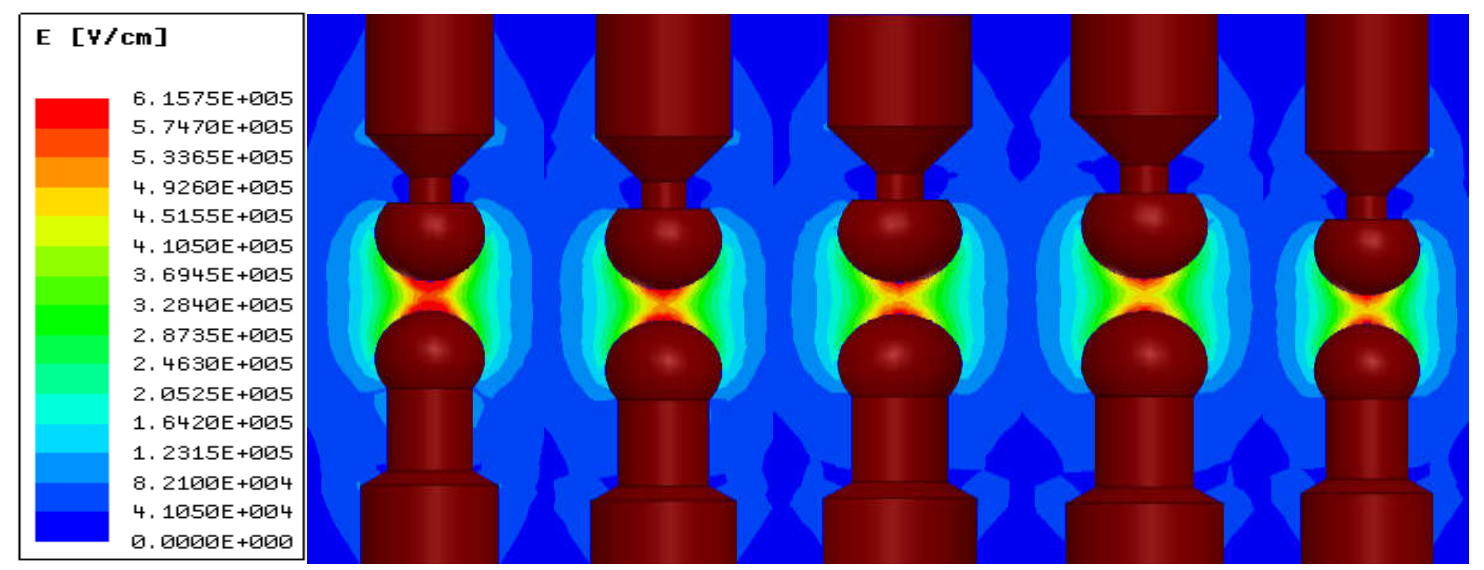
a) $\mathrm{MO}$
(b) $\mathrm{CO}(\mathrm{c}) \mathrm{POA}$
(d) POB
(e) POC

Fig. 8. Electric field distribution and its maximum electric field intensity

\subsection{Mesh}

The experimental setup with $12.7 \mathrm{~mm}$ diameter spherical electrodes with $3.8 \mathrm{~mm}$ gap distance consisted as illustrated in Fig. 8. The exact geometry of electrodes used in the experimental setup has been explained in Fig. 9. The 3-D model was chosen for this spherical electrode system models. Normal mesh is taken and the section of the model between the electrodes identified from the experimental results, where the particles are more likely to travel and contact with the edge of the electrodes. The mesh for all samples show similar pattern.

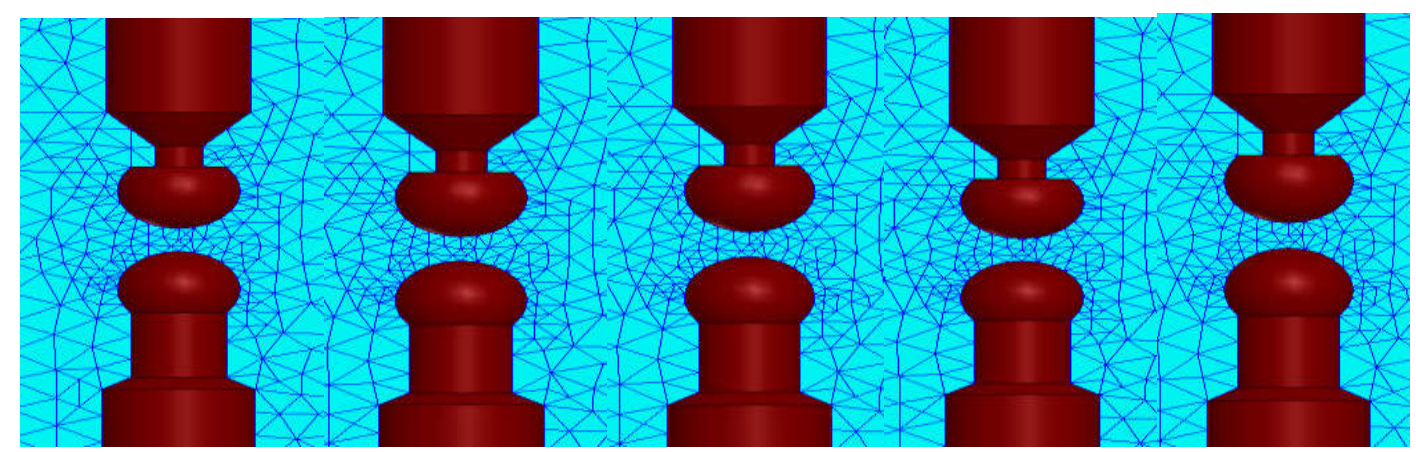
a) $\mathrm{MO}$
(b) $\mathrm{CO}$
(c) POA
(d) POB
(e) POC

Fig. 9. 50\% breakdown voltage based mesh method of all samples 


\section{CONCLUSION}

The lightning impulse breakdown voltages for both PO and CO are slightly lower than MO. The $50 \%$ breakdown voltage for all vegetable oils is comparable to MO respectively. Based on Weibull distribution fitting, withstand voltage at $1 \%$ breakdown probability of POA were close to the MO. ANSYS is used in this paper to build up the three-dimension calculation model. A calculation method of transient electric field intensity distribution inside atransformer impressed with impulse test voltages as a contribution to the design of internal insulation of power transformers is proposed. The 3-D asymmetrical electric field analysis and the obtained electric field distribution are visualized. Result from experimental and simulation shows PO have a more strength than MO. In order to maintain its dielectric properties under the strong electric fields is to make sure the characteristic of dielectric strength is strong. The presented results show appropriate covenant with experimental. The result shows palm oil can be use an alternative to replace mineral oil in power transformer. However, in order to replace it more research has to do and many experimental parameters, such as different gap distance, electrode configuration, temperature and applied voltage need to investigate.

\section{ACKNOWLEDGEMENTS}

The authors would like to thank Ministry of Education and National Defence University of Malaysia for funding under Fundamental Research Grant Scheme, FRGS (FRGS/2/2014/TK03/UPNM/02/2) and Research Acculturation Grant Scheme, RAGS (RAGS/1/2014/TK03/UPNM/1).

\section{REFERENCES}

[1] Hopkinson P, Dix L, McShane CP, Moore H R, Moore S, Murphy J, Prevost T, Beaster B. Progress report on natural esters for distribution and power transformers.In IEEE Power and Energy Society General Meeting, 2009, pp. 3-5 
[2] Azis N, Jasni J, Ab KadirM Z A, Mohtar M N. Suitability of palm based oil as dielectric insulating fluid in transformers.Journal of Electrical Engineering and Technology, 2014, $9(2): 662-669$

[3] Malaysian Palm Oil Board (MPOB).About palm oil.Washington DC: MPOB, 2015

[4] Kano T, Suzuki T, Oba R, Kanetani A, Koide H. Study on the oxidative stability of palm fatty acid ester (PFAE) as an insulating oil for transformers.In IEEE International Symposium onElectrical Insulation, 2012, pp. 22-25

[5] Liu Q, Wang Z D. Breakdown and withstand strengths of ester transformer liquids in a quas uniform field under impulse voltages.IEEE Transactions on Dielectrics and Electrical Insulation, 2013, 20(2):571-579

[6] Liu Q. Electrical performance of ester liquids under impulse voltage for application in power transformers.Phd thesis, England:University of Manchester, 2011

[7] International Electrotechnical Commission (IEC). IEC 60897: Methods for the determination of the lightning impulse breakdown voltage of insulating liquids.Geneva: IEC, 1987

[8] KatimN I A, Ishak M T, Ishak A M, Thein Y V, Azis N,Kadir M Z A A, Jasni J, Yunus R, Yaakub Z. Examination on the lightning breakdown strength of biodegradable oil under quasi-uniform field. In IEEE International Conference on Power and Energy, 2014, pp. 17-20 [9] Katim N I A, Ishak M T, Ishak A M, Kadir M Z A A. Behavior of biodegradable oil under impulse voltages. Applied Mechanics and Materials, 2015, 785:320-324

\section{How to cite this article:}

Amin N A M, Ishak M T, Katim N I A, Hamid M H A, Hashim F R, Din M F M. Lightning impulse investigation on vegetables oils and simulation of electric field distribution. J. Fundam. Appl. Sci., 2017, 9(3S), 373-383. 